\title{
ESTUDO DE DORMENTES DE AÇO SOB SOLICITAÇÕES VERTICAIS, LONGITUDINAIS E TRANSVERSAIS EM VIA PERMANENTE FERROVIÁRIA
}

\author{
STUDY OF STEEL SLEEPERS OF ROAD PERMANENT RAILWAY UNDER VERTICAL, \\ LONGITUDINAL AND CROSS LOADS
}

\author{
Rudney C. Queiroz, Luttgardes de Oliveira Neto \\ Departamento de Engenharia Civil e Ambiental - Faculdade de Engenharia \\ Universidade Estadual Paulista - UNESP - Bauru (SP). E-mail: rudney@ feb.unesp.br; lutt@ feb.unesp.br
}

\begin{abstract}
RESUMO
Este artigo apresenta os resultados de pesquisas desenvolvidas em modelos em escala real, estudando o comportamento de dormentes de aço sob a ação de solicitações estáticas verticais, longitudinais e transversais. Para a realização desta pesquisa, foram executados modelos, com trilhos TR-68, fixados com sistema elástico, sobre sete dormentes de cada tipo, separadamente, embutidos em lastro padrão com $35 \mathrm{~cm}$ de altura e sobre base de solo compactado com $30 \mathrm{~cm}$ de altura. Para as provas de carga, foram construídos sistemas de reação dos esforços horizontais e verticais com o objetivo de aplicação das solicitações. O sistema de leituras e aquisição de dados foi totalmente informatizado, obtendo-se, em tempo real, os valores de esforços e deslocamentos. Os resultados obtidos foram comparados com os da mesma via instalada com dormentes de madeira, de concreto protendido monobloco e de concreto bibloco. Os resultados analisados forneceram parâmetros inéditos no Brasil e de grande importância para o projeto de via permanente ferroviária moderna, utilizando dormentes de aço.
\end{abstract}

Palavras-chave: Dormentes de aço. Via permanente ferroviária. Superestrutura ferroviária.

\begin{abstract}
This article presents the results of research conducted on full-scale models, studying the behavior of steel sleepers under the action of static loads, in vertical, longitudinal and transverse directions. For the research models were run with rails TR-68, fixed with elastic system on seven sleepers each type, separately, embedded in standard ballast with $35 \mathrm{~cm}$ height and on the basis of compacted soil with $30 \mathrm{~cm}$ thick. For the load tests were constructed using reaction systems of vertical and horizontal forces with the objective of applying the requests. The system of readings and data acquisition was fully computerized, obtaining in real time the values of forces and displacements. The results were compared with those installed in the same way with sleepers of wood, mono-block and bi-block prestressed concrete. The analyzed results provided unprecedented parameters in Brazil and of great importance for the design of modern railway permanent way, using steel sleepers.
\end{abstract}

Keywords: Steel sleepers. Railway permanent way. Railway superstructure.

\section{INTRODUÇÃO}

Ao longo do histórico das ferrovias, foram desenvolvidas várias pesquisas, buscando conhecer o comportamento estrutural da grade da via embutida na camada de lastro. Esses estudos objetivaram estimar os valores das resistências laterais e longitudinais, principalmente para o dimensionamento de trilhos longos soldados e a economia na manutenção da via permanente.

Vários autores apresentaram resultados de pesquisas teóricas e experimentais, podendo-se citar Sonneville e Bentot (1953), Dogneton (1975), Peixoto Junior (1981), Kerr (1993), Kish e Mui (1996), Bousquet (1997), Kish et al. (1998), Queiroz (1990-1993-2002). Essas pesquisas contemplaram, 
sobretudo, dormentes de madeira, de concreto bibloco e de concreto protendido monobloco, sendo poucas as pesquisas com dormentes de aço.

No Brasil, ainda se utilizam, em larga escala, dormentes de madeira, mas, devido a problemas ambientais e custos elevados, tem-se buscado alternativas em dormentes de concreto e de aço. Os primeiros dormentes de aço remontam ao início das ferrovias, na primeira metade do século XIX.

Foram desenvolvidos diversos tipos de dormentes de aço, diferenciando-se muitos deles, na forma geométrica, por simples detalhes ou pela fixação dos trilhos. Em síntese, consistem numa chapa laminada, em forma de "U" invertido, curvada em suas extremidades, a fim de formar garras que penetram no lastro e opõem-se ao deslocamento longitudinal e transversal da via.

O dormente de aço é relativamente leve $(0,8 \mathrm{kN}$ por unidade para bitola larga). De fácil manejo de assentamento, oferece facilidade na manutenção da bitola, não sofre ação de insetos e possui alta durabilidade. Em contrapartida, pode apresentar problemas de fissura nas proximidades dos trilhos devido à fadiga, bem como apresentar maior elasticidade na grade da via. A taxa de dormentação fica entre 1.700 a 1.800 dormentes por quilômetro.

Como vantagens dos dormentes de aço, podem ser citadas, ainda:

a) fácil moldagem por laminação e estamparia;

b) resistência elevada;

c) bom embutimento no lastro;

d) boas condições de recondicionamento e reutilização.

Como desvantagens, citam-se:
a) massa reduzida;
b) tráfego mais ruidoso;
c) problemas com o isolamento elétrico;
d) custo ainda elevado.

\section{MATERIAIS E MÉTODOS}

O dormente de aço utilizado na presente pesquisa (Figura 1a) é o modelo SIDEX-99 UIC-865 1/2 para carga de $300 \mathrm{kN}$ e para bitola larga $(1.600 \mathrm{~mm})$. Constitui-se em uma chapa estampada com abas nas extremidades, de modo a permitir um maior embutimento no lastro e melhorar a estabilidade lateral.

Os dormentes foram assentados e embutidos no lastro com espaçamento entre-eixos de $60 \mathrm{~cm}$, fixados aos trilhos com grampo elástico tipo Pandrol e com almofada de apoio intermediária entre o patim do trilho e o dormente (Figura 1b).

Para o desenvolvimento da pesquisa, foi construído, no Departamento de Engenharia Civil da Unesp - Bauru, um trecho experimental de via férrea composto por sete dormentes apoiados sobre camada de lastro padrão com altura de $30 \mathrm{~cm}$, e esta sobre camada de solo compactado. Os quatro tipos de dormentes - de aço, de madeira, de concreto protendido monobloco e de concreto bibloco foram ensaiados separadamente, montando-se as grades das vias sobre a mesma camada de lastro em condições similares. 

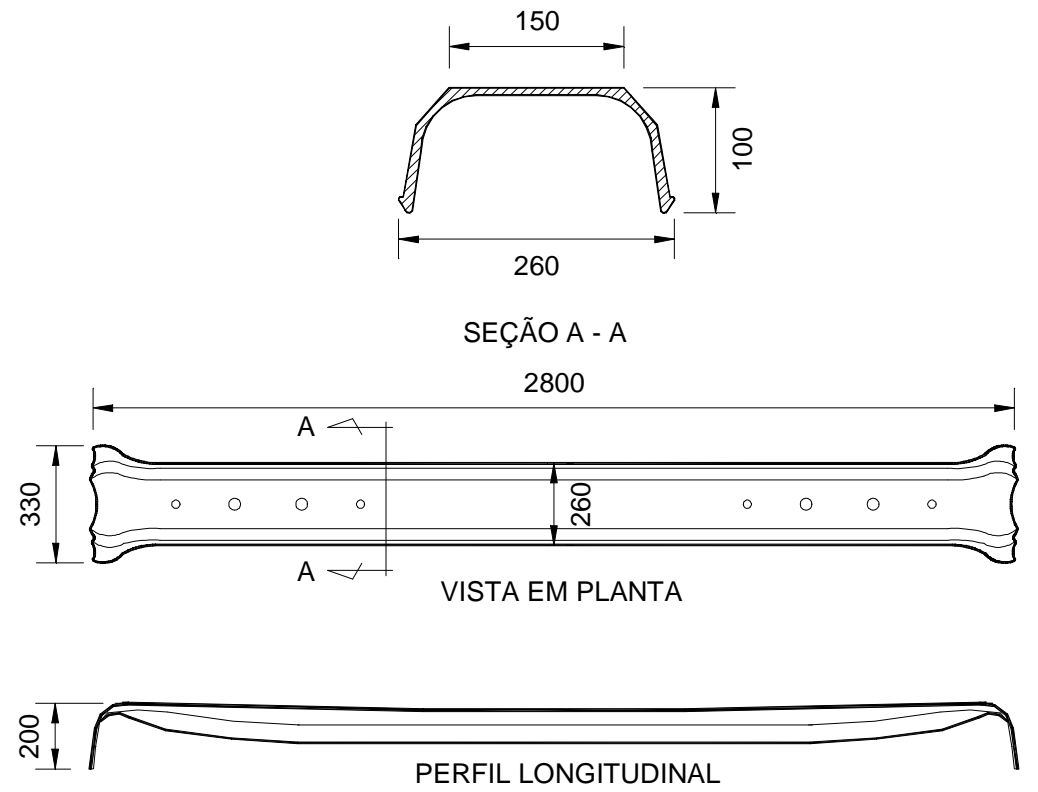

MEDIDAS EM MILÍMETROS

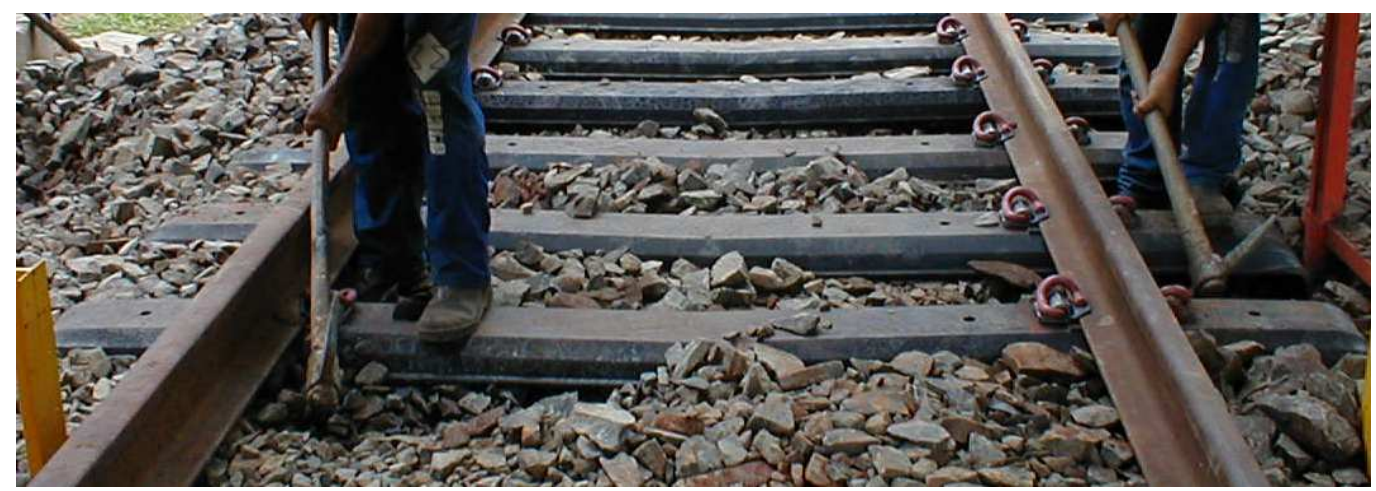

Figura 1: Esquema e foto do dormente de aço utilizado na pesquisa Fonte: o autor.

Para a aplicação das solicitações verticais, longitudinais e transversais e medição dos deslocamentos, foi montado o sistema de reação e de aplicação de cargas. Para as cargas verticais, foi executado um sistema de reação engastado no terreno e composto por uma viga metálica de perfil I sobre a via (Figura 2a). As cargas horizontais (longitudinais e transversais) foram aplicadas com base em sistemas de reação engastados no terreno; o primeiro, composto por viga em perfil I (longitudinal, Figura 2b); e o segundo, por viga com perfil H (transversal, Figura 2c), travado lateralmente, com sistema de encaixe no boleto do trilho externo e chapa de fixação do macaco.

Os esforços foram aplicados por meio de cilindros hidráulicos com células de carga, e os deslocamentos foram obtidos com transdutores eletrônicos ligados a um sistema de leitura e aquisição de dados (Figura 2d).

As cargas foram aplicadas até obterem-se deformações máximas longitudinais e transversais de aproximadamente $30 \mathrm{~mm}$, sendo os valores limites considerados de $15 \mathrm{~mm}$, pois deslocamentos acima desse nível podem ser vistos como prejudiciais para a geometria da via e o tráfego. 


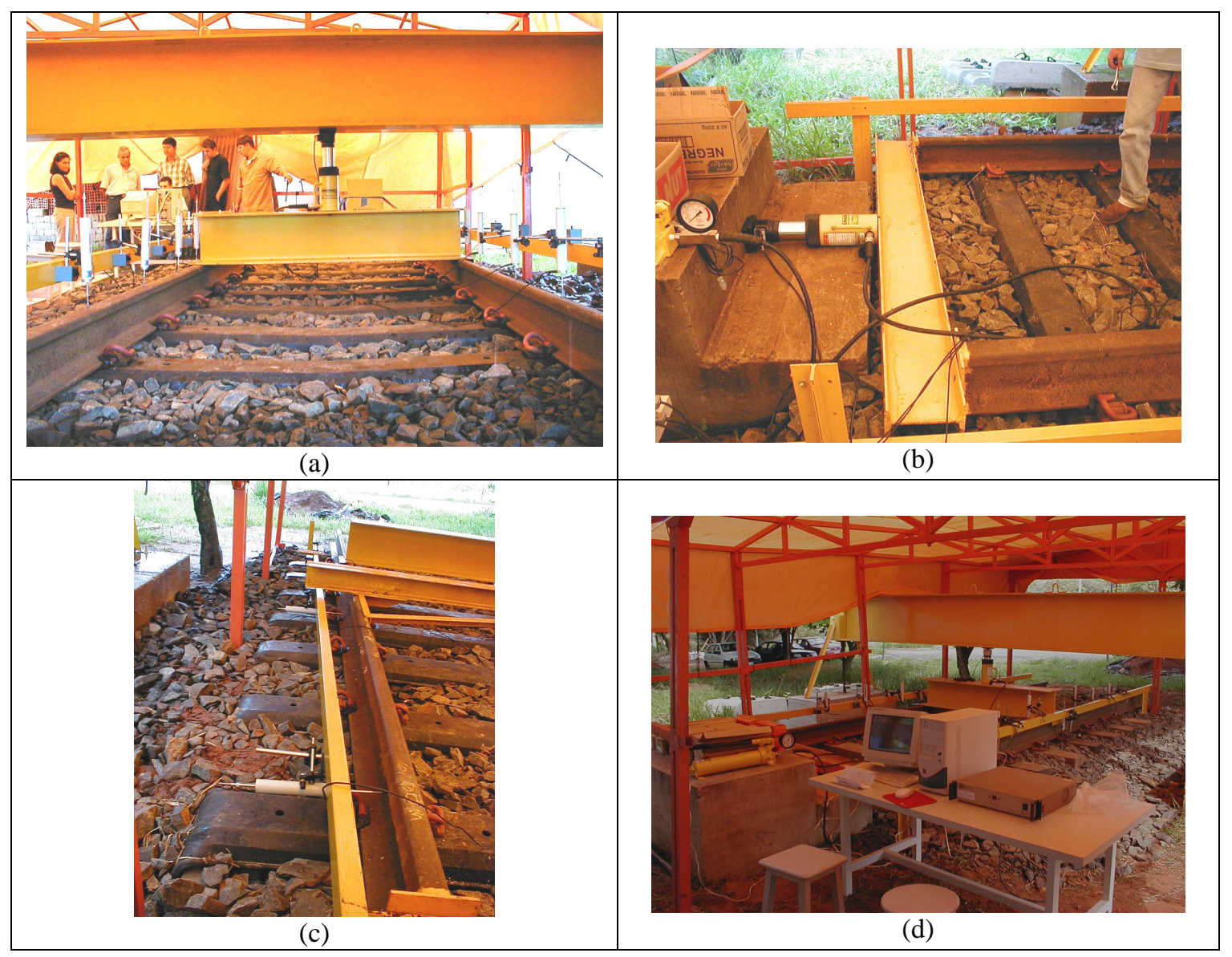

Figura 2: (a) sistema de reação vertical; (b) aplicação dos esforços longitudinais; (c) aplicação dos esforços transversais; (d) sistema de leituras e aquisição de dados. Fonte: o autor.

\section{RESULTADOS OBTIDOS E ANÁLISE}

Quanto às solicitações verticais, em pesquisa realizada anteriormente (Queiroz, 1990), foram obtidas as deformações elásticas dos dormentes de concreto protendido monobloco, de madeira e de aço.

A Figura 3 mostra a comparação das deformações individuais de cada tipo de dormente sob o par de cargas que representa a ação das rodas do veículo.

Verifica-se que o dormente de aço sofre maiores deformações em seu comprimento, comparadas com as apresentadas pelos outros dois tipos. Essa maior flexibilidade do dormente de aço diminui a qualidade estrutural da grade da via, pois resulta em maiores deformações verticais localizadas da via sob a ação das cargas dos veículos.

A Figura 4 apresenta os resultados obtidos para os ensaios globais do trecho de via com dormentes de aço sob carregamentos longitudinais e transversais e respectivos deslocamentos totais. 


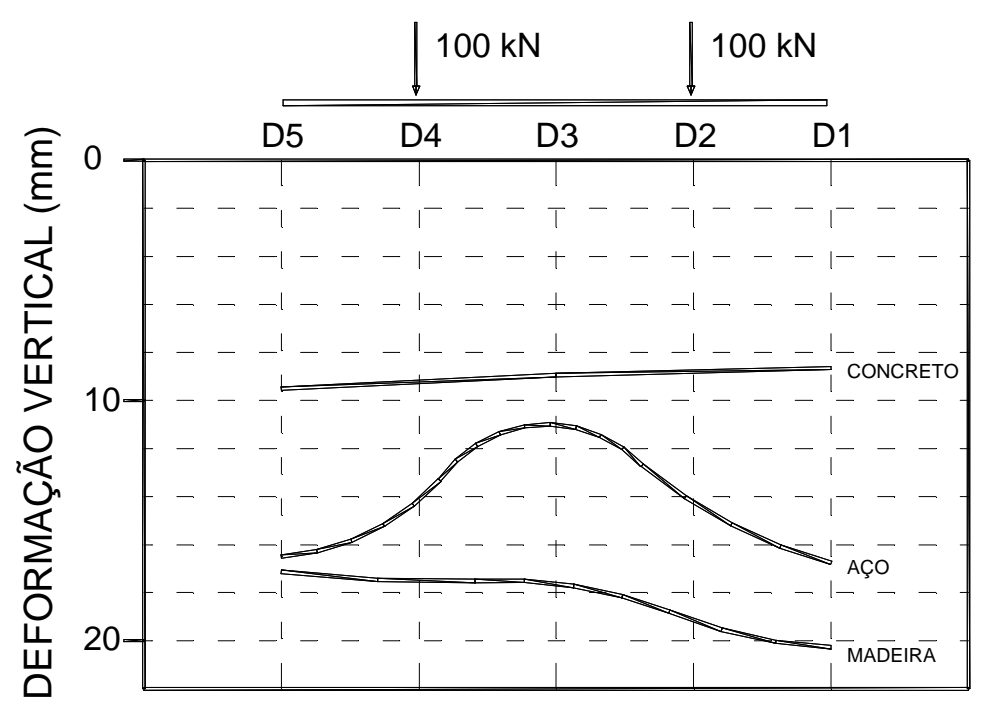

Figura 3: Deformações elásticas dos dormentes de concreto protendido monobloco, de aço e de madeira sob ação das cargas do veículo; escala aumentada. Fonte: Queiroz, 1990.
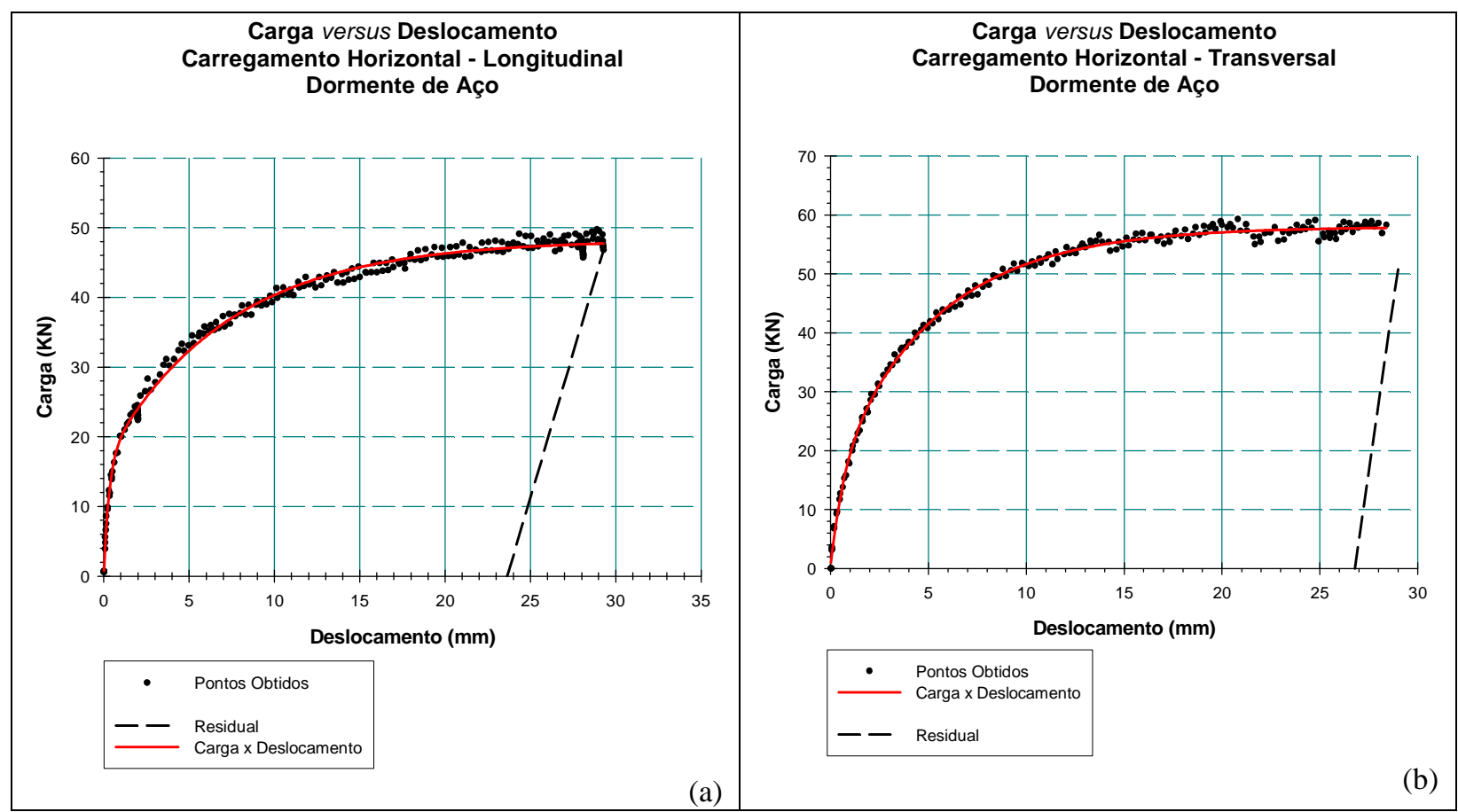

Figura 4: Diagramas cargas versus deslocamentos longitudinais (a) e transversais (b) para trecho de via com dormentes de aço. Fonte: Queiroz, 2002.

Pode-se observar o mesmo comportamento geral do trecho de via nas duas situações de carregamento, com grande rigidez inicial. Para um deslocamento global inicial de $5 \mathrm{~mm}$, a força total aplicada é de $32 \mathrm{kN}$ na direção longitudinal e de $41 \mathrm{kN}$ na direção transversal, demonstrando que o embutimento das abas de extremidade do dormente resulta em boa interação dormente/lastro e grande 
rigidez lateral conjunta. Já na direção longitudinal, o embutimento das dobras laterais do perfil do dormente garante essa interação dormente/lastro.

Em ambas as direções, a partir desses níveis de carregamento, os deslocamentos aumentam em alto gradiente, demonstrando que a interação dos dormentes com o lastro começa a ser prejudicada, possivelmente, devido às deformações excessivas do dormente e ao deslocamento de blocos junto às abas do dormente e consequente desagregação do lastro.

As Tabelas 1 e 2 apresentam os valores das solicitações individuais por dormente para deslocamentos longitudinais e transversais de $15 \mathrm{~mm}$, respectivamente.

\begin{tabular}{c|c}
\multicolumn{2}{c}{ Tabela 1: Solicitações por dormente para deslocamentos longitudinais de $\mathbf{1 5} \mathbf{~ m m}$} \\
\hline Tipo de dormente & $\begin{array}{c}\text { Solicitação por dormente para } \\
\text { deslocamento de } \mathbf{1 5} \mathbf{~} \mathbf{~} \mathbf{( e m} \mathbf{~ k N})\end{array}$ \\
\hline Madeira & 7,57 \\
\hline Concreto protendido monobloco & 9,86 \\
\hline Concreto bibloco & 8,86 \\
\hline Aço & 6,43 \\
\hline
\end{tabular}

Fonte: Queiroz, 2002.

Para as solicitações longitudinais, o dormente de aço mostra-se mais deformável, apresentando o menor valor de carregamento necessário para um deslocamento global de $15 \mathrm{~mm}$ dentre os tipos de dormentes comparados. Verifica-se que a flexibilidade e o embutimento do dormente de aço no lastro conferem valores próximos ao de madeira para deslocamentos longitudinais.

Considerando-se as solicitações transversais, o dormente de aço evidencia um comportamento estrutural com boa rigidez axial, apresentando valores equivalentes ao do dormente de concreto protendido monobloco. Isso se deve às abas existentes nas extremidades, que penetram $20 \mathrm{~cm}$ na camada de lastro promovendo com este uma boa interação.

Tabela 2: Solicitações por dormente para deslocamentos transversais de $15 \mathrm{~mm}$

\begin{tabular}{c|c}
\hline Tipo de dormente & $\begin{array}{c}\text { Solicitação por dormente para } \\
\text { deslocamento de } \mathbf{1 5} \mathbf{~ m m ~ ( e m ~ k N )}\end{array}$ \\
\hline Madeira & 4,86 \\
\hline Concreto protendido monobloco & 6,14 \\
\hline Concreto bibloco & 9,14 \\
\hline Aço & 8,14 \\
\hline
\end{tabular}

Fonte: Queiroz, 2002.

Considera-se esse valor de $15 \mathrm{~mm}$ como limite para a intervenção na manutenção das juntas de dilatação para trilhos longos e no arredondamento das curvas. Esse deslocamento admitido para cada 
extremidade de trilho totaliza $30 \mathrm{~mm}$ de deslocamento relativo máximo. Na direção longitudinal, com uma folga de segurança na junta de $20 \mathrm{~mm}$, totaliza-se um valor máximo de abertura de junta de 50 $\mathrm{mm}$.

\section{CONCLUSÕES}

Conforme exposto nesta pesquisa, pode-se considerar que os dormentes de aço:
a)
Oferecem menor desempenho quanto aos esforços verticais, apresentando maiores deformações quando comparados aos outros tipos de dormentes;
b) Apresentam a menor das resistências longitudinais dentre as grades das vias ensaiadas com os diversos tipos de dormentes;
c) Oferecem bom desempenho para solicitações transversais, principalmente em trechos em curva;
d) Podem ser utilizados em vias de tráfego menos intenso, como em desvios com carga leve por eixo, como trens de passageiros e trens urbanos;
e) Podem ser utilizados em desvios e pátios de manobras com baixas velocidades e intensidades de tráfego.

\section{REFERÊNCIAS}

BOUSQUET, C. Essai sur modèle du comportement de ponts-rails réalisés à partir de poutres préfabriquées en béton précontraint par adhérence. Revue Générale des Chemins de Fer, Paris, no 12. p. 63-66, 1997. ISSN 0035-3183 CODEN RGCFAI.

DOGNETON, P. The experimental determination of the axial and lateral track-ballast resistance. In: SYMPOSIUM ON RAILROAD TRACK MECHANICS, 1975, Princenton. The Princenton University, Apr. 1975. Princenton, NJ. p. 14-16. 1975.

KERR, A. D. On the stress analysis of rails and ties. American Railway Engineering Association AREA, Bulletin n. 659, p. 19-43, 1993.

KISH, A.; MUI, W. A brief synopsis on the track lateral shift problem. American Railway Engineering Association - AREA, Bulletin n. 746, p. 155-168, 1996.

KISH, A.; CLARK, D, W.; THOMPSON, W. Recent investigations on the lateral stability of wood and concret tie tracks. American Railway Engineering Association - AREA, Bulletin n. 752, p. 252265. 1998.

PEIXOTO JUNIOR, T. de L. Comprimento de linha, tensões e temperatura. 2. ed. São Carlos, SP: Escola de Engenharia de São Carlos, USP, 1981. 71 p.

QUEIROZ, R. C. Contribuição ao estudo experimental das resistências horizontais e módulo de deformação em modelo de via permanente ferroviária. 2002. Tese (Livre Docência em Transporte Ferroviário) Departamento de Engenharia Civil - Faculdade de Engenharia - Universidade Estadual Paulista - Unesp. Bauru, SP, 134 p. 
QUEIROZ, R. C. Estudo experimental de tensões e deformações em camadas da infra-estrutura e superestrutura ferroviária. 1990. 140 f. Tese (Doutorado em Geotecnia) - Escola de Engenharia de São Carlos da Universidade de São Paulo, São Carlos, SP, 1990.

QUEIROZ, R. C.; GAIOTO, N. Dormentes de concreto protendido monobloco: tensões e deformações no lastro ferroviário. Revista Ibracom - Instituto Brasileiro do Concreto, São Paulo, ano 3, n. 8, p. 22-24, abr./maio/jun. 1993.

SONNEVILLE, R.; BENTOT, A. Elasticité et résistance latérale de la voie. Bulletin de l'Association du Congrès des Chemins de Fer. vol. XXXIII nº 2 p. 685-716. 1953-1956. 